\title{
Maintaining independence after a fall
}

\author{
$\mathrm{AB}$ Spinks ${ }^{1}$ and $\mathrm{J}$ Wasiak $^{2}$ \\ ${ }^{1}$ Griffith University, School of Medicine and ${ }^{2}$ Monash University, School of Public Health and Preventive Medicine
}

\section{Summary}

Falls have a significant impact upon independent living ability in older people, with fall-related fractures one of the leading predictors of having to move into assisted living facilities. The loss of independence associated with a severe fall is often accompanied by a decline in physical, social, emotional and economic well-being. Rehabilitation programmes to restore functional ability following a fall have a greater chance of success if they adopt a multi-disciplinary approach and, if appropriate, are conducted in the patient's own home. Additional multi-component interventions that improve confidence and reduce the risk of subsequent falls may confer benefits by assisting individuals independently to perform activities of daily living.

Keywords: Falls, older people, independence, activities of daily living, rehabilitation.

\section{Introduction}

The loss of independence, often associated with societal pressure to leave one's home to reside in an assisted care facility is one of the greatest fears faced by older people living in the community. ${ }^{1}$ Falls are a sudden event that can have immediate and catastrophic repercussions on the ability of an older person to continue living independently. ${ }^{2}$

The purpose of this review is to describe the literature which has explored the consequences of falls among older people and evaluated interventions that may be implemented after a fall has occurred. We searched Medline and the Cochrane Database using a combination of the search terms 'independence', 'functional ability', 'fall', 'fracture', 'rehabilitation' and 'activities of daily living'. A summary of the current literature addressing the maintenance of independence following a fall was compiled based on these search results.

Address for correspondence: Anneliese Spinks, Griffith University, School of Medicine, University Drive, Meadowbrook, Queensland, 4131, Australia. Email: a.spinks@griffith.edu.au

\section{The value of independence}

Independence is generally understood to imply freedom from the control, influence, support or aid from others. For older people, the loss of independence is inevitably equated with an unrecoverable demise leading to poorer overall quality of life compounded by worsening physical, social, cognitive, emotional and socio-economic circumstances. This coincides with the placement of a substantial burden on either family members or members of the wider community who must step in to assist the older individual with performing necessary daily tasks.

The loss of independence may initially be partial or total, ranging from milder inconveniences such as losing the ability (or permission) to drive, to requiring assistance in performing routine daily activities necessary to maintain life. In order to define and understand the implications of losing independence, researchers have previously categorized routine, everyday tasks into basic and instrumental activities of daily living. ${ }^{3,4}$

Basic activities of daily living are those that are integral in maintaining life with the level of dignity that defines the human condition. These include bathing, eating, toileting and dressing, and the loss of dependence in these activities is defined as requiring more than occasional help in order to perform these tasks. ${ }^{3}$

Instrumental activities of daily living are those that require less intrusion into personal space but are nonetheless required to maintain daily life. These include tasks such as the preparation of meals, housework, preparing shopping lists and performing laundry and shopping duties. ${ }^{4}$

\section{The problem of falling}

Although older age is generally correlated with declining levels of independence, the loss of functional ability is normally a gradual process as daily tasks slowly become more difficult to perform over time. In contrast, the loss of functional 
ability due to a fall or other sudden medical event (e.g. stroke or cardiac event) has an abrupt and instantaneous effect.

A fall is defined as 'unintentionally coming to the ground or some lower level and other than as a consequence of sustaining a violent blow, loss of consciousness, sudden onset of paralysis as in stroke or an epileptic seizure. ${ }^{5}$ As muscle strength, stability co-ordination, balance and confidence decline with increasing age, the risk of falling steadily rises.

It has been estimated that about one third of all people aged over 65 years fall every year, ${ }^{6}$ with this proportion increasing with older age. It has only been more recently recognized, however, that falls and their consequences are one of the major contributors to the loss of independence among older people. ${ }^{7}$ Approximately one third of older people experiencing an injurious fall require assistance with activities of daily living, ${ }^{8}$ with half of these requiring assistance for a period of six months or longer.

On the more severe end of the spectrum, fallrelated injuries are often a direct cause of admission into assisted care facilities; $;^{9,10}$ however, falling may also erode independence in more subtle ways. Even among those without serious injury, falls can lead to reduction in mobility and the ability to perform daily activities due to loss of confidence and the awareness that one is vulnerable or weak..$^{8,11}$

\section{Fall-related injuries}

Injuries that result from a fall physically disenable the individual by reducing the functionality of the site of injury. Although injuries that result from falls may heal if managed appropriately, the time required for total recovery often takes longer in older people compared with younger, fitter individuals. ${ }^{12}$ Sometimes the damage caused by the injury is irreversible and full physical functionality is not able to be fully restored due to unrecoverable muscle wastage and co-ordination loss that occurs while the injured site is not being used.

Fractures are the most severe injuries associated with falls among older people, and often occur due to a delayed response in acting to break a fall. ${ }^{13}$ Hip fractures and wrist fractures in particular are frequent, with wrist fractures likely when a hand is outstretched to break a fall either forwards or backwards, while hip fractures often result after a sideways fall. ${ }^{14}$ Sprains, bruises, cuts and grazes, although less serious than a fracture, may also result in a period of activity restriction that may impact upon ability to perform activities of daily living.

The consequences of severe fall-related injury can be devastating, particularly if a fracture occurs. Up to one quarter of patients falling and sustaining a hip fracture may be in long-term care facilities one year post-fracture, and at least a half do not return to their pre-fracture level of functioning. ${ }^{2}$

In a comparative study of 12 and 24 month functionality among patients with hip fracture against community-matched controls, there were 26 more individuals unable to walk 10 feet across a room for every 100 hip fractures. ${ }^{2}$ Additionally, 22 more individuals were not able to transfer in and out of bed and six more required assistance for grooming compared with what would be expected after 2 years of ageing.

\section{Fear of falling}

The activity restricting implications of fall-related physical injuries are fairly easy to comprehend. Less apparent, but of significant consequence, are the psychological effects of falling which act through eroding confidence in performing essential daily activities, which may have been conducted prior to the fall. ${ }^{15,16}$

The task of quantifying the effect of fear of falling on independence is not as straightforward as measuring the direct physical and socioeconomic consequences of falls. ${ }^{17}$ However, there is growing evidence that fear of falling significantly contributes to activity restriction among older people, which in turn leads to greater disability and loss of independence. ${ }^{16}$ Fear of falling has been associated with lower activities of daily living scores, ${ }^{18}$ slower gait, ${ }^{19}$ use of a walking aid, ${ }^{19}$ emotional depression, ${ }^{18,19}$ and poor health status. ${ }^{20}$ Moreover, fear of falling is greater among those who have experienced a fall ${ }^{21}$ and increases with the number of falls experienced. ${ }^{16}$ At the more severe end of the fear spectrum it has been estimated that as many as one quarter of older individuals who have experienced a fall may suffer from post-traumatic stress disorders. ${ }^{22}$

Fear of falling among older people has been reported to be the most important factor predicting the avoidance of activities deemed necessary for 
daily living ${ }^{16,23}$ with more than two-thirds of the elderly reporting avoiding at least some activities such as walking, stooping, lifting and reaching. ${ }^{16}$ The consequences of restricted physical activity in turn generate a negative cycle that compounds further losses in flexibility, strength and coordination. ${ }^{11,24}$

\section{Risk and protective factors affecting independence following a fall}

It has often been noted that individuals with similar levels of physical impairment are capable of varying levels of functionality in daily life. This is due to a number of factors that influence capacity for independence, including the availability of support from family members or the broader community, aspects of the physical environment in which the individual must function and individual physiological differences including age, gender, mental capacity, co-morbidities and medication use. ${ }^{25-27}$

These factors all interact to influence how quickly and completely functionality is recovered following a fall. However, the strongest predictors of functional recovery are pre-fracture physical functioning and cognitive ability. ${ }^{28}$ Other less important predictors of functional recovery include male gender and balance, ${ }^{27}$ while patients who are older than 85 years of age, live alone prior to sustaining a fracture and have multiple comorbidities have been found to be at greater risk for non-recovery of basic activities of daily living. ${ }^{26}$

\section{Interventions to improve functional independence after a fall}

Although recovery and prognosis following an injurious fall are generally considered to be poor, it is also recognized that many older individuals do recover fully from their injuries and manage to return to their prior level of functionality. ${ }^{29}$ Most of the available literature describing interventions to restore functional independence consists of trials that have recruited hip fracture patients. Hip fractures are perhaps the most deleterious of the common fall-related injuries among older people and thus efforts to improve outcomes among this population have been the most prolific.

Patients who have sustained a hip fracture are generally expected to return to pre-morbid levels of basic functionality approximately 4-6 weeks after their injury, while more advanced functionality will take longer to achieve. ${ }^{30}$ Basic daily living activities such as bathing and dressing are more likely to be recovered than instrumental activities such as shopping and housework. ${ }^{26}$ However, for those who do not regain competence in basic activities of daily living, bathing is the activity most likely to require assistance. ${ }^{29}$

Interventions may directly affect capacity for independence by restoring functional ability through physical rehabilitation. Alternatively, interventions may be aimed at reducing the likelihood of subsequent disability through providing clinical assessment, educational advice and services to prevent further falls.

In the previous section it was described how a range of protective and risk factors may influence the rate of recovery and likelihood of regaining functionality following a fall. The success of any intervention which aims to assist recovery and hence maintain the likelihood of independence is often similarly dependent upon these factors. ${ }^{28}$

\section{Rehabilitation programmes}

The main goal of rehabilitation following a fallrelated injury is to restore physical functionality and promote strength, co-ordination, flexibility and balance. ${ }^{30}$ Early mobilization within 2 days after surgery to repair a hip fracture has been demonstrated to improve patient mobility and increase the likelihood of patients being discharged directly home. ${ }^{31}$ However, a Cochrane review assessing mobilization strategies following hip fracture surgery in adults concluded that the evidence base for effective rehabilitation strategies is limited, with no one mobilization strategy emerging as the preferred treatment. ${ }^{32}$

It has been suggested that the success of hospital-based rehabilitation programmes depends upon the co-ordination of multidisciplinary teams consisting of experts in a variety of medical, allied-health, social and educational fields. ${ }^{33} \mathrm{~A}$ systematic review of multidisciplinary programmes for patients recovering from hip fracture found that the research evaluating the benefit of a variety of programmes is somewhat difficult to synthesize and compare given the heterogeneity of outcome measures and programme protocols. ${ }^{28}$ However, this review did conclude that collaborative 
programmes employing health workers from a variety of disciplines that assist patients to recover functionality and return home are likely to be effective in achieving these aims. Moreover, it has been established that multidisciplinary programmes that incorporate staff training and individualized care protocols improve long-term functionality compared with usual hospital care. ${ }^{34}$

Rehabilitation setting. Comparative trials have evaluated the effectiveness of rehabilitation programmes in various settings, including hospital wards, in-patient rehabilitation facilities, and the patient's own home. In general, however, the location of rehabilitation is largely determined by the patient's pre-injury level of functioning and previous living circumstances. Before any rehabilitation programme is decided upon, it is necessary to perform an assessment of the patient's mental status, pre-morbid activity, co-morbidities and level of available social support in order to determine the suitability of the proposed structure and setting of the rehabilitation. ${ }^{30}$

Dedicated rehabilitation facilities have been found to enable better outcomes than hospital settings, resulting in a greater likelihood of the patient returning to their own home and improved functional capability. ${ }^{35,36}$ This is due mainly to the increased contact time with physicians and health workers providing dedicated physiotherapy and occupational therapy services compared with standard hospital facilities. However, rehabilitation facilities are generally suited to patients who are healthier and who have a higher level of pre-injury functionality. ${ }^{35}$

Home-based rehabilitation, often referred to as Early Supported Discharge, offers patients rehabilitation goals that are more relevant to daily activity and focuses on improving functional capacity in the home environment. A number of trials have favourably compared the outcomes of home-based rehabilitative therapy with care provided in either a hospital or other institutional setting. ${ }^{3-39}$ Benefits of home-based rehabilitation have included improved physical independence, ${ }^{38}$ confidence in avoiding subsequent falls, ${ }^{38}$ lower caregiver burden at 12 months $^{38}$ and lower functional decline. ${ }^{39}$ However, care of the patient is transferred onto either their family or members of the community, meaning that this option is only feasible if adequate social support networks are available. ${ }^{39}$ Moreover, home-based rehabilitation programmes are more likely to be successful in mentally stable patients and those considered to have adequate physical and cognitive capacity to participate in a rehabilitation programme. ${ }^{40}$

\section{Multi-component strategies to decrease functional difficulties}

Multi-component strategies that deliver services beyond traditional rehabilitation have also been evaluated. An intervention model evaluated the effectiveness of having a gerontologic advanced practice nurse act as a post-acute care co-ordinator for a 6-month period following hip fracture among an elderly population. ${ }^{41}$ The co-ordinator maintained contact with each patient in the intervention group by visits and phone calls on a bi-weekly basis and observed health and function of the patient. Compared with controls who received conventional post-acute care, patients in the intervention group had improved functionality at 12 months in several instrumental activities of daily living. However, there were no differences between the groups in general health, depression or living situation.

A similar multi-component programme involving occupational and physical therapy sessions in the home in conjunction with home modification, educational advice, muscle strength and balance training demonstrated superior outcomes among participants receiving the programme compared with those receiving no treatment. ${ }^{42}$ Improved outcomes included competence in instrumental activities of daily living, greater self efficacy and less fear of falling.

\section{Intervention to address fear of falling}

A small number of interventions have aimed to reduce the effect that fear of falling has upon activity restriction in older people. These interventions have used combinations of educational and exercise strategies to increase confidence in engaging in activities of daily living. ${ }^{42-46}$ There is some evidence of a modest beneficial effect including reduction in fear of falling, promotion of activity and improvements in balance, social functioning and mobility. ${ }^{42,42-46}$ However, not all interventions have shown a positive effect at reducing falls or fear of falling. ${ }^{43}$ 
Interventions aimed at preventing subsequent falls

Incident falls may exacerbate previous injuries and hence worsen functional independence following a serious fall-related injury. ${ }^{47}$ Hence a number of interventions exist to identify and mitigate fall hazards among patients at risk.

Clinical assessment and co-ordinated care programmes. The purpose of clinical assessment following a fall is to identify and reduce physiological factors that may put the individual at risk of subsequent falls. This may be done by revealing previously undiagnosed conditions such as problems with hearing, vision, cognition and balance. These conditions can hence be appropriately managed. ${ }^{10}$

One falls prevention programme utilizing a clinical assessment protocol reported fewer fallrelated admissions and hospital bed days among patients receiving a detailed home assessment compared with a control group who received no intervention. ${ }^{48}$ Patients within the intervention group also demonstrated higher indicators of functionality and mobility within the community. The assessment included a review of current medications, blood pressure, ECG, cognition, visual acuity, hearing, vestibular dysfunction, balance, mobility and footwear. Education and support was provided to assist patients in addressing any concerns that were raised by the assessment.

Pharmaceutical modification. Medication use has been associated with increased falls in older people, particularly psychotropic drugs and multiple drug regimes. ${ }^{15,49,50}$ The increased fall risk exerted by medications is mainly due to adverse effects on alertness, postural balance and co-ordination. ${ }^{51}$

Trials aiming to reduce overall medication among community-dwelling elderly patients have reported significant reductions in the number of total falls and fall-related injuries. ${ }^{52-54}$ However, it has been concluded that patient compliance with permanent withdrawal may be difficult to achieve. ${ }^{54}$ This is largely due to the negative effects experienced by individuals stopping medications that have previously been relied upon for relief of psychosomatic symptoms including insomnia and anxiety.
Environmental changes and hazard reduction in the home. There is moderate evidence that assessment of potential hazards in the home environment is warranted after a fall, particularly as most falls occur in or around the home. ${ }^{8}$ Compared with a control group receiving no intervention, falls were significantly reduced among patients who received a home visit by an occupational therapist who assessed the environment and advised on hazard reduction and behaviour modification. ${ }^{55}$ In addition, aspects of the home and community environment were significantly related to participation in activities of daily living among adults in a rehabilitation cohort. ${ }^{56}$

Nutrition and vitamin supplementation. It is recommended that elderly patients who have sustained a fall be nutritionally assessed and advised to consume a high protein diet with vitamin and mineral supplementation. ${ }^{33} \mathrm{~A}$ metaanalysis investigating the effect of vitamin $\mathrm{D}_{3}$ supplementation on bone health outcomes concluded that there was fair evidence that supplementation of vitamin $\mathrm{D}_{3}$ in conjunction with calcium has a small beneficial effect compared with placebo on bone mineral density, and reduced the likelihood of fractures resulting from a fall. ${ }^{57}$ This beneficial effect was most likely to be seen among women.

Exercise training. Exercise training has been shown to positively improve balance, strength, flexibility and co-ordination among older people at risk of falling, ${ }^{58-60}$ with some trials also demonstrating a reduction in falls ${ }^{61,62}$ and fear of falling. ${ }^{63}$

Hip protectors. It has been suggested that hip protectors may improve falls self-efficacy by increasing confidence in performing routine daily tasks, thus decreasing reliance on assistance with daily living. ${ }^{63}$ However, a Cochrane review found no statistically significant benefit of wearing hip protectors among community-dwelling older people and also found that compliance in their use was generally poor. ${ }^{64}$ Their use may be more effective at improving confidence in residential care settings rather than in the community.

Multifactorial interventions. Multifactorial interventions are based on the notion that falls 
result from a combination of factors, and hence fall reduction strategies will be most successful if they target a range of potential risk factors. A multifactorial intervention is likely to employ various approaches to risk modification including clinical assessment, educational advice, behaviour modification, review of medications, environmental hazard reduction and exercise training.

In support of the multifactorial approach, one fall prevention trial did demonstrate that a significantly greater reduction in falls eventuated from a combination of three single interventions (exercise training, vision correction, home hazard assessment) than from either of the interventions implemented on their own. ${ }^{65}$ Other trials have similarly demonstrated improvements in overall health and a reduction in falls among those who have fallen previously. ${ }^{66,67}$

\section{Conclusion}

Falls and fall-related injuries significantly limit the ability of older people to perform activities of daily living, leading to demise in physical, social and functional independence. Severe injuries, particularly fractures, have the biggest impact on functional ability. However, the erosion of confidence through fear of subsequent falls may also lead to a restriction of physical and social activities.

Rehabilitation programmes provide the most direct means to improve outcomes following a fall-related injury, and these programmes are most likely to be successful if they consist of multidisciplinary teams that focus on the individual needs and circumstances of the individual. Homebased rehabilitation therapy has the best chance of restoring functional outcomes that are relevant to maintaining performance in daily activities. However, home-based programmes are only suited to a subset of individuals for whom adequate social support networks are available. Dedicated rehabilitation units that offer co-ordinated health, educational and social services may confer superior functional outcomes to conventional hospitalbased rehabilitation services.

A number of geriatric-focused multi-disciplinary programmes that incorporate clinical assessment with education, balance and exercise training, home hazard assessment and review of patient medications have been shown to moderately improve functional outcomes among older individuals who have experienced a fall. Interventions that seek to address fear of falling and reduce the potential for subsequent falls and related injuries are also likely to have a slight beneficial influence on preserving functional ability and independence.

\section{References}

1 Quine S, Morrell S. Fear of loss of independence and nursing home admission in older Australians. Health Soc Care Comm 2007; 15: 212-20.

2 Magaziner J, Fredman L, Hawkes W et al. Changes in functional status attributable to hip fracture: a comparison of hip fracture patients to community dwelling-aged. Am J Epidemiol 2003; 157: 1023-31.

3 Katz S, Ford AB, Moskowitz RW, Jackson BA, Jaffe MW. Studies of illness in the aged. The index of ADL: A standardized measure of biological and psychological function. JAMA 1963; 185: 914-19.

4 Lawton MP, Brody E. Assessment of older people: self-maintaining and instrumental activities of daily living. Gerontologist 1979; 9: 179-86.

5 Gibson MJ, Andres RO, Isaacs B, Radebaugh T, Worm-Petersen J. The prevention of falls in later life. A report of the Kellogg International Work Group on the prevention of falls by the elderly. Dan Med Bull 1987; 34 (suppl 4): S1-24.

6 Centre for Disease Control and Prevention (CDC). Self-reported falls and fall related injuries among persons aged $>$ or $=65$ years - United States, 2006. MMWR Morb Mortal Wkly Report 2008; 57: 225-29.

7 Bialoszewski D, Slupik A, Lewczuk E, Gotlib J, Mosiolek A, Mierzwinska A. Incidence of falls and their effect on mobility of individuals over 65 years of age relative to their place of residence. Ortop Traumatol Rehabil 2008; 10: 441-48.

8 Schiller JS, Kramarow EA, Dev AN. Fall injury episodes among non-institutionalized older adults: United States, 2001-2003. Adv Data 2007; 21 (392): 1-16.

9 Tinetti ME, Williams CS. Falls, injuries due to falls, and the risk of admission to a nursing home. N Engl J Med 1997; 337: 1279-84.

10 Rubenstein LZ. Falls in older people: epidemiology, risk factors and strategies for prevention. Age Ageing 2006; 35: ii37-41.

11 Yardley L, Smith H. A prospective study of the relationship between feared consequences of falling and avoidance of activity in communitydwelling older people. Gerontologist 2002; 42: $17-23$. 
12 Gosain A, DiPietrio LA. Aging and wound healing. World J Surg 2004; 28: 321-26.

13 Adelsberg S, Pitman M, Alexander H. Lower extremity fractures: relationship to reaction time and coordination time. Arch Phys Med Rehabil 1989; 70: 737-39.

14 Nevitt MC, Cummings SR. Type of fall and risk of hip and wrist fractures: the study of osteoporotic fractures. The Study of Osteoporotic Fractures Research Group. J Am Geriatr Soc 1993; 41: 1226-34.

15 Faulkner KA, Cauley JA, Studenski SA. Lifestyle predicts falls independent of physical risk factors. Osteoporosis Int 2009 [Epub].

16 Bertera EM, Bertera RL. Fear of falling and activity avoidance in a national sample of older adults in the United States. Health Soc Work 2008; 33: 54-62.

17 Moore DS, Ellis R. Measurement of fall-related psychological constructs among independentliving older adults: a review of the research literature. Aging Ment Health 2008; 12: 68499.

18 Burker EJ, Wong H, Sloane PD, Mattingly D, Preisser J, Mitchell CM. Predictors of fear of falling in dizzy and non-dizzy elderly. Psychol Aging 1995; 10: 104-10.

19 Kressig RW, Wolf SL, Sattin RW et al. Associations of demographic, functional, and behavioural characteristics with activity-related fear of falling among older adults transitioning to frailty. J Am Geriatr Soc 2001; 49: 145662.

20 Lach HW. Incidence and risk factors for developing fear of falling in older adults. Public Health Nurs 2005; 22: 45-52.

21 Tinetti ME, Baker DI, Gottschalk M et al. Home-based multicomponent rehabilitation for older person after hip fracture: a randomized trial. Arch Phys Med Rehabil 1999; 80: 916-22.

22 Chung MC, McKee KJ, Austin C et al. Post-traumatic stress disorder in older people after a fall. Int J Geriatr Psychiatry 2009 [Epub].

23 Deshpandne N, Metter EJ, Lauretani F, Bandinelli S, Guralnik J, Ferruci L. Activity restriction induced by fear of falling and objective and subjective measures of physical function: a prospective cohort study. J Am Geriatr Soc 2008; 56: 615-20.

24 Cumming RG, Sakeld G, Thomas M, Szonyi G. Prospective study of the impact of fear of falling on activities of daily living, sf-36 scores, and nursing home admission. J Gerontol: Med Sci 2000; 55 (a): M299-305.

25 Egol KA, Koval KJ, Zuckerman JD. Functional recovery following hip fracture in the elderly. J Orthop Trauma 1997; 11: 594-99.
26 Koval KJ, Skovron ML, Aharanoff GB, Zuckerman JD. Predictors of functional recovery after hip fracture in the elderly. Clin Orthop 1998; 348: 22-28.

27 Folden S, Tappen R. Factors influencing function and recovery following hip repair surgery. Orthop Nurs 2007; 26: 234-41.

28 Cameron ID. Coordinated multidisciplinary rehabilitation after a hip fracture. Disabil Rehabil 2005; 27: 1081-90.

29 Curry LC, Hogstel MO, Davis GC. Functional status in older women following hip fracture. $J$ Adv Nurs 2003; 42: 347-54.

30 Dionyssiotis Y, Dontas IA, Economopoulos D, Lyritis GP. Rehabilitation after falls and fractures. J Musculoskelet Neuronal Interact 2008; 8: 244-50.

31 Oldmeadow LB, Edwards ER, Kimmel LA, Kipen E, Robertson VJ, Bailey MJ. No rest for the wounded: early ambulation after hip surgery accelerates recovery. ANZ J Surg 2006; 76: 607-11.

32 Handoll $\mathrm{HH}$, Sherington C. Mobilisation strategies after hip fracture in adults. Cochrane Database Syst Rev 2007: CD001704.

33 Chilov M, Cameron ID, March LM. Evidence-based guidelines for fixing broken hips: an update. Med J Aust 2003; 179: 48992.

34 Stenvall M, Oloffson B, Nyberg L, Lundstrom M, Gustafson Y. Improved performance in activities of daily living and mobility after a multidisciplinary postoperative rehabilitation in older people with femoral neck fracture: a randomized controlled trial with 1-year follow-up. J Rehabil Med 2007; 39: 232-38.

35 Munin MC, Seligman K, Drew MA et al. Effect of rehabilitation site on functional recovery after hip fracture. Arch Phys Med Rehabil 2005; 86: 367-72.

36 Kane RL, Chen Q, Finch M, Blewett L, Burns R, Moskowitz M. The optimal outcomes of post-hospital care under Medicare. Health Serv Res 2000; 35: 615-61.

37 Ziden L, Frandin K, Kreuter M. Home rehabilitation after hip fracture: a randomized controlled study on balance confidence, physical function and everyday activities. Clin Rehabil 2008; 22: 1019-33.

38 Crotty M, Whitehead CH, Gray S, Finucane PM. Early discharge and home rehabilitation after hip fracture achieves functional improvements: a randomized controlled trial. Clin Rehabil 2002; 16: 406-13.

39 Giusti A, Barone A, Oliveri M, Pizzonia M, Razzano M, Palummeri E, Pioli G. An analysis of the feasibility of home rehabilitation among 
elderly people with proximal femoral fractures. Arch Phys Med Reabbil 2006; 87: 826-31.

40 Crotty M, Whitehead C, Miller M, Gray S. Patient and caregiver outcomes 12 months after home-based therapy for hip fracture: a randomized controlled trial. Arch Phys Med Rehabil 2003; 84: 1237-39.

41 Krichbaum K. GAPM Postacute care coordination improves hip fracture outcomes. West J Nurs Res 2007; 29: 523-44.

42 Gitlin LN, Winter L, Dennis MP, Corcoran M, Schinfeld S, Hauck WW. A randomized trial of a multicomponent home intervention to reduce functional difficulties in older adults. J Am Geriatr Soc 2006; 54: 809-16.

43 Rucker D, Rowe BH, Johnson JA et al. Educational intervention to reduce falls and fear of falling in patients after fragility fractures: results of a controlled pilot study. Prev Med 2006; 42: 316-19.

44 Tennstedt S, Howland J, Lachman M, Peterson E, Kasten L, Jette A. A randomized, controlled trial of a group intervention to reduce fear of falling and associated activity restriction in older adults. J Gerontol B Psychol Sci Soc Sci 1998; 53: P384-92.

45 Brouwer BJ, Walker C, Rydahl SJ, Culham EG. Reducing fear of falling in seniors through education and activity programs: a randomized trial. J Am Geriatr Soc 2003; 51: 829-34.

46 Sattin RW, Easley KA, Wolf SL, Chen Y, Kutner $\mathrm{MH}$. Reduction in fear of falling through intense Tai chi exercise training in older, transitionally frail adults. J Am Geriatr Soc 2005; 53: 116878.

47 Di Monaco M, Vallero F, Tappero R, De Lauso L, De Toma E, Cavanna A. Incident falls impair ability to function in hip-fracture survivors: a prospective study of 95 elderly women. Arch Gerenol Geriatr 2008; [Epub].

48 Lightbody E, Watkins C, Leathley M, Sharma A, Lye M. Evaluation of a nurse-led falls prevention programme versus usual care: a randomized controlled trial. Age Ageing 2002; 31: 203-10.

49 Coutinho ES, Fletcher A, Bloch KV, Rodrigues LC. Risk factors for falls with severe fractures in elderly people living in a middle income country: a case control study. BMC Geriatr 2008; 8: 21.

50 Landi F, Onder G, Cesari M et al. Psychotropic medications and risk for falls among community-dwelling frail older people: an observational study. J Gerontol A Biol Sci Med Sci 2005; 60: 622-26.

51 Vestergaard P. Skeletal effects of central nervous system active drugs: anxiolytics, sedatives, antidepressants, lithium and neuroleptics. Curr Drug Saf 2008; 3: 185-89.
52 Van Der Welde N, Meerding WJ, Looman CW, Pols HA, Van Der Cammen TJ. Cost effectiveness of withdrawal of fall-risk-increasing drugs in geriatric outpatients. Drugs Aging 2008; 25 : 521-29.

53 Weber V, White A, McIlvried R. An electronic medical record (EMR)-based intervention to reduce polypharmacy and falls in an ambulatory rural elderly population. J Gen Intern Med 2008; 23: 399-404.

54 Campbell AJ, Robertson MC, Gardner MM, Norton RN, Buchner DM. Psychotropic medication withdrawal and a home-based exercise program to prevent falls: a randomized, controlled trial. J Am Geriatr Soc 1999; 47: 850-53.

55 Cumming RG, Thomas M, Szonyi G. Home visits by an occupational therapist for assessment and modification of environmental hazards: a randomized trial for falls prevention. J Am Geriatr Soc 1999; 47: 1471-72.

56 Keysor JJ, Jette AM, Coster W, Pvru Bettger J, Haley SM. Association of environmental factors with levels of home and community participation in an adult rehabilitation cohort. Arch Phys Med Rehabil 2006; 87: 1566-75.

57 Cranny A, Horsley T, O’Donnell S. Effectiveness and safety of Vitamin D in relation to bone health. Evid Rep Technol Assess (Full Rep) 2007; 158: 1-235.

58 Melzer I, Benjuya N, Kaplanski J. Effect of physical training on postural control of elderly. Harefuah 2005; 144: 839-44.

59 Sohng KY, Moon JS, Song HH, Lee KS, Kim YS. Fall prevention exercise program for fall risk factor reduction of the community-dwelling elderly in Korea. Yonset Med J 2003; 44: 883-91.

60 Binder EF, Brown M, Sinacore DR, Steger-May K, Yarasheki KE, Scechtman KB. Effects of extended outpatient rehabilitation after hip fracture: a randomized controlled trial. JAMA 2004; 18: 837-46.

61 Faber MJ, Bosscher RJ, Chin A, Paw MJ, van Wieringen PC. Effects of exercise programs on falls and mobility in frail and pre-frail older adults: a multicenter randomized controlled trial. Arch Phys Med Rehabil 2006; 87; 885-96.

62 Weerdesteyn V, Rijken H, Geurts AC, Smite-Engelsman BC, Mulder T, Duysens J. A five-week exercise program can reduce falls and improve obstacle avoidance in the elderly. Gerontology 2006; 52: 131-41.

63 Cameron ID, Stafford B, Cumming RG et al. Hip protectors improve falls self-efficacy. Age Ageing 2000; 29: 57-62.

64 Parker MJ, Gillespie WJ, Gillespie LD. Hip protectors for preventing hip fractures in older people. Cochrane Database of Systematic Reviews 
2005, issue 3, art no: CD001255.

DOI: $10.1002 / 14651858 . C D 001255$.pub3.

65 Day L, Fildes B, Gordon I, Fitzharris M, Flamer H, Lord S. Randomised factorial trial of falls prevention among older people living in their own homes. BMJ 2002; 325: 1177.

66 Clemson L, Cumming RG, Kendig H, Swann M, Heard R, Taylor K. The effectiveness of a community-based program for reducing the incidence of falls in the elderly: a randomized trial. J Am Geriatr Soc 2004; 52: 1487-94.

67 Rizzo JA, Baker DI, McAvay G, Tinetti ME. The cost-effectiveness of a multifactorial targeted prevention program for falls among community dwelling elderly persons. Med Care 1996; 34: 954-69. 
Reproduced with permission of the copyright owner. Further reproduction prohibited without permission. 